\title{
ANÁLISE DA CONCILIAÇÃO EM MATÉRIA TRIBUTÁRIA À LUZ DA INDISPONIBILIDADE DO INTERESSE PÚBLICO
}

\author{
SIMINI, Danilo Garnica ${ }^{1}$ \\ ARAÚJO, Lucas Pereira ${ }^{2}$ \\ BORGES, Diego da Mota ${ }^{2}$
}

RESUMO: A conciliação surge com o passar dos anos como um meio de solução de conflitos, podendo ser utilizado, no curso do processo, ou, antes dele ser instaurado, como forma de possibilitar a resolução da lide. Este método, que não se confunde com mediação e arbitragem, encontra-se previsto em uma série de dispositivos legais. Todavia, a aplicação da conciliação em causas relacionadas ao direito público, especialmente demandas tributárias, ainda é objeto de polêmica haja vista que a aplicação do instituto configuraria uma possível violação ao princípio da indisponibilidade do interesse público. Sendo assim, o presente trabalho visa analisar, por meio de pesquisa bibliográfica, a conciliação enquanto método de solução de conflitos e, principalmente, se a aplicação da conciliação em matéria tributária constitui violação ao princípio da indisponibilidade do interesse público.

Palavras-chave: Conciliação. Direito tributário. Interesse público. Solução de conflitos.

\section{ANALYSIS OF RECONCILIATION IN THE LIGHT OF TAX MATTERS OF PUBLIC INTEREST UNAVAILABILITY}

SUMMARY: The reconciliation comes over the years as a means of conflict resolution and can be used in the proceedings, or before it is introduced as a way of enabling the resolution of the dispute. This method that should not be confused with mediation and arbitration, is provided in a series of legal devices. However, the application of the reconciliation in causes related to public law, especially tax claims, is still the subject of controversy, so long as the application of the institute would set a possible violation of the principle of unavailability of the public interest. Thus, the present work analyzes, by means of literature, conciliation as a method of conflict resolution, and especially the application of conciliation in tax matters constitute a breach of the principle of availability of public interest .

Keywords: Reconciliation. Ttax law. Public interest. Conflict resolution.

\section{INTRODUÇÃO}

A resolução dos conflitos sociais em um Estado Democrático de Direito como Brasil ocorre mediante o exercício, por este ente soberano, do monopólio da Jurisdição, a qual, atualmente se mostra insuficiente para atender o grande contingente formado por aqueles que se socorrem da tão assoberbada estrutura judiciária, fortemente reconhecida pelo trâmite processual moroso e ineficaz.

Neste panorama, como forma de, no mínimo, amenizar os problemas gerados pela judicialização exagerada dos conflitos sociais, surgem às chamadas técnicas de solução alternativa de contendas, as quais

\footnotetext{
${ }^{1}$ Advogado; Mestrando em Direito pela UNESP de Franca; Especialista em Direito Público pela Escola Paulista da Magistratura; Especialista em Direito Tributário pela Universidade Anhanguera; Coordenador da Comissão de Cultura da OAB de Ituverava (Gestão 2013/2015). E-mail: danilosimini @ gmail.com

${ }^{2}$ Advogado; Pós-graduando (especialização) em Direito Processual Civil pela USP de Ribeirão Preto. E-mail: lpereiraaraujo@hotmail.com
} 
são representadas, basicamente, pelos institutos da mediação, arbitragem e conciliação. Tais técnicas, muito embora não tenham sido exploradas na intensidade com que ocorre no direito comparado, estão previstas no ordenamento pátrio com o fito de diminuir a sobrecarga que assola o Poder Judiciário, bem como atribuir celeridade as demandas que já se encontrem sub judice.

Especificamente em relação à conciliação, que é objeto de análise neste ensaio, verifica-se que sua utilização como meio alternativo de solução do conflito é amplamente admitida no âmbito privado quando se está diante de um direito disponível.

No entanto, por força da cultura do litígio que permeia os jurisconsultos brasileiros, formou-se uma grande resistência por parte da doutrina e também da jurisprudência, na aplicação deste instituto em uma relação tributária, a qual envolve diretamente o interesse público, o qual é insuscetível de disponibilização.

Muito embora seja praticamente pacífica a possibilidade de se transacionar em questões relativas ao direito tributário diante da prévia existência de lei que autorize sua realização (art. 171, do Código Tributário Nacional), renomados juristas, através de consistentes argumentos, sustentam a impossibilidade de utilizar esta técnica por força do princípio da indisponibilidade do interesse público.

Em virtude disto, é que se justifica a escolha do tema abordado no presente trabalho, haja vista que é preciso fazer uma cuidadosa análise da possibilidade da conciliação, não somente sob a ótica do princípio da indisponibilidade do interesse público, mas também à luz os princípios constitucionais da eficiência (art. 37, caput), da duração razoável do processo (art. $5^{\circ}$, inciso LXXIV) e da dignidade da pessoa humana (art. $1^{\circ}$, inciso III).

Neste contexto, o presente trabalho tem por finalidade a análise pormenorizada do instituto da conciliação, a sua previsão na legislação tributária e também se a sua utilização sob a ótica constitucional, constituiria ou não violação do princípio da indisponibilidade do interesse público. Tal análise será feita essencialmente por meio de revisão bibliográfica.

Para alcançar o objetivo ora proposto, primeiramente serão conceituadas as formas de solução pacífica de conflitos tais como a mediação e arbitragem, demonstrando as suas diferenças em relação à conciliação. Em seguida, se fará uma abordagem da transação como causa extintiva do crédito tributário, para que assim, seja possível analisar, em ato contínuo a conciliação em matéria tributária sob a ótica do princípio da indisponibilidade do interesse público e dos princípios constitucionais acima referidos.

Assim, com a utilização dos mecanismos aqui expostos, será possível chegar a uma conclusão satisfatória e plausível acerca da conciliação e a ocorrência ou não da violação do princípio da indisponibilidade do interesse público.

\section{A CONCILIAÇÃO COMO MEIO DE SOLUÇÃO DE CONFLITOS}

É cediço que o convívio em sociedade gera inúmeros conflitos de interesse. Não é menos certo que, muitas vezes não é possível que as partes alcancem, por si, a solução adequada por suas próprias vias, tendo em vista que não se concebe em um Estado de Democrático de Direito a utilização da autotutela ${ }^{3}$.

Em razão disso, tomou o Estado para si o dever de tutela da vida em sociedade, vale dizer, o poder-dever de solucionar conflitos de interesse, impondo sua vontade, mesmo que em contrariedade à vontade dos particulares, ao que se denominou Jurisdição.

\footnotetext{
${ }^{3}$ Entenda-se por autotutela o exercício pela própria parte de meios para a defesa de seu interesse. Aliás, tal vedação culminou na criação do crime de exercício arbitrário das próprias razões, previsto no art. 345 do Código Penal.

Nucleus,v.12,n.1,abr.2015
} 
A jurisdição pode ser conceituada como a função do Estado destinada à solução imperativa de conflitos e exercida mediante a atuação da vontade do direito em casos concretos (DINAMARCO, 2004, p.329). Assim, dá-se sempre a substituição de atividades de todas as partes pela atividade jurisdicional do Estado (DINAMARCO, 2004, p. 331).

Em sucintas palavras, por Jurisdição compreenda-se o pode-dever do Estado-Juiz não só de dizer qual deve ser a solução aplicada para determinadas situações conflituosas, mas também a capacidade de garantir a imposição de suas decisões. Superada a questão atinente a Jurisdição, como regra na solução dos conflitos, é necessário consignar que existem meios alterativos à solução pelo Estado.

O que se preconiza atualmente é que o Estado não é o único - e, algumas vezes, sequer é o mais adequado ente vocacionado para esta função, que pode muito bem ser exercida por particulares, algumas vezes com resultados mais proveitosos do que aqueles obtidos no âmbito do judiciário (ALVIM, 2011, p.197).

Nesse cenário de métodos alternativos à solução de conflitos é que a conciliação se insere, mas não como método alternativo propriamente dito, advirta-se, sim como um meio capaz de possibilitar a resolução do conflito, seja no curso do processo, seja antes dele ser instaurado.

A ressalva feita acima se justifica pela razão de que os meios propriamente ditos alternativos de solução de conflitos têm sua aplicação em momentos alheios ao processo, vale dizer, a mediação e a arbitragem são métodos extraprocessuais, de modo que quando atuam não há falar-se, ainda, em jurisdição e processo, muito embora possa ocorrer a modalidade de conciliação pré-processo.

Assim sendo, cumpri trazer à baila o conceito de mediação e arbitragem, de modo a consignar que estes não se confundem com a conciliação, para após adentrar-se no estudo desta forma de resolução de conflitos.

Por arbitragem deve ser entendida a situação onde "um terceiro escolhido pelas partes tem a incumbência de resolver o conflito, sendo uma forma de heterocomposição" (SILVA, 2004, p. 77). Perceba-se que na arbitragem as partes, por vontade própria, escolhem uma terceira pessoa que deverá intervir na solução do conflito.

Já a "mediação é o método consensual de solução de conflitos, que visa à facilitação do diálogo entre as partes, para que melhor administrem seus problemas e consigam, por si só, alcançar uma solução" (SOUSA, 2005). Diferentemente da arbitragem, onde uma pessoa é escolhida impondo sua vontade, na mediação o terceiro nada impõe apenas influi de modo a facilitar que as próprias partes alcancem uma decisão mais acertada.

Feitas as necessárias considerações acerca da arbitragem e da mediação, cumpri-nos agora definir o instituto da conciliação. Por primeiro, apenas a título de introdução no conceito deste instituto, ressaltamos que a conciliação deve ser entendida como o "processo pelo qual o conciliador tenta fazer que as partes evitem ou desistam da jurisdição" (FIUSA, 1995, p. 56), ou, ainda, um “ajuste, acordo, entendimento entre partes em litígio, pondo fim à lide" (GUIMARÃES, 2010, p. 188).

Diferentemente da mediação, onde também há um terceiro que atua sem impor sua vontade ( situação diversa ocorre, pois, na arbitragem, mediante a imposição pelo arbitro da decisão), a conciliação não será considera concluída se as partes não lograrem no acordo, enquanto a mediação terá ocorrido, mesmo não havendo ajuste entre os interessados.

A conciliação se reveste de duas modalidades, quer se dê no âmbito do processo, quer seja 
realizada antes de sua existência, ao que a doutrina ${ }^{4}$ tem batizado de qualificação endoprocessual extraprocessual, respectivamente.

No Direito Brasileiro o instituto da conciliação está presente em diversos Diplomas legais, a exemplo do que ocorre na Consolidação das Leis do Trabalho, nos artigos 846 e 850, no Código Civil, no artigo 840 e seguintes, no Código de Processo Civil, especificamente nos artigos 125, inciso IV, 331, 447 a 449, e também na Lei dos Juizados Especiais (Lei no 9.099/95), conforme se depreende do art. $2^{\circ}$. Devese ressaltar também que o Novo Código de Processo Civil (Lei 13.105/2015) que entrará em vigor apenas em 2016 reconhece a importância da conciliação, mediação e outros métodos alternativos de solução de conflitos, estabelecendo que estes devam ser estimulados por juízes, advogados, defensores públicos e membros do Ministério Público.

A legislação brasileira tem enfatizado em diversos dispositivos a necessidade de utilização do instituto da conciliação no curso do processo. Logo, pode-se afirmar que existe contribuição para a prática desse meio alternativo de solução de litígio, o qual é de grande valia aos jurisdicionados.

Não há, por isso, qualquer dúvida quando se estabelece a conciliação entre direitos privados e disponíveis, a exemplo de litígios que envolvam cobrança de determinada quantia, tendo em vista que o poder das partes em se deixarem flexibilizar em pró do fim do litígio prevalece. É que nesses casos a disposição ocorre unicamente no âmbito dos particulares, que podem, sopesando a morosidade processual e o risco da demanda optarem pela composição ${ }^{5}$.

Feitas tais considerações, deve-se agora analisar o instituto da conciliação em matéria tributária, especialmente seus requisitos e peculiaridades, a fim de que se possa chegar a uma conclusão se a conciliação em matéria tributária constitui ou não violação ao princípio da indisponibilidade do interesse público.

\section{TRANSAÇÃO COMO CAUSA DE EXTINÇÃO DO CRÉDITO TRIBUTÁRIO}

A relação jurídico-tributária apresenta nitidamente caráter obrigacional, possuindo aspectos subjetivos e objetivos. No que diz respeito aos primeiros, tem-se no polo ativo ente político (União, Estados, Distrito Federal e Municípios) na qualidade de credor e, no polo passivo, contribuinte ou responsável tributário, cujo dever é o cumprimento da obrigação. Por outro lado, em relação ao aspecto objetivo, pode-se dizer que esta relação possui por objeto uma prestação positiva ou negativa devida pelo devedor em face do credor, fazendo com que Geraldo Ataliba afirme que o "objeto da relação tributária é o comportamento consistente em levar dinheiro aos cofres públicos" (2012, p. 23).

Feitas tais considerações, deve-se lembrar que a obrigação tributária é classificada em principal e acessória. A obrigação tributária principal surge com a ocorrência do fato gerador, tem por objeto o pagamento de tributo ou penalidade pecuniária e extingui-se juntamente com o crédito dela decorrente (artigo 113, parágrafo $1^{\circ}$, do Código Tributário Nacional). De outra parte, a obrigação tributária acessória decorre da legislação tributária e tem por objeto prestações, positivas ou negativas, nela previstas no interesse da arrecadação ou da fiscalização dos tributos (artigo 113, parágrafo $2^{\circ}$, do Código Tributário Nacional).

\footnotetext{
${ }^{4}$ DINAMARCO, Cândido Rangel. Intervenção de terceiros. 3. ed. São Paulo: Malheiros, 2000 APUD JR., Evaldo Rosário de Oliveira. Acesso à justiça e as vias alternativas para solução de controvérsias: mediação, conciliação e arbitragem.

${ }^{5}$ A palavra composição, embora também assuma outros significados, aqui é utilizada como sinônimo de conciliação. Nucleus,v.12,n.1,abr.2015
} 
Desta forma, pode-se dizer que a obrigação tributária principal é obrigação de dar (pagar tributo e multa), bem como apresenta natureza patrimonial. A obrigação tributária acessória, por sua vez, é obrigação de fazer ou deixar de fazer (ex: emitir notas fiscais ou não rasurar os livros contábeis) e, portanto, não apresenta caráter patrimonial.

Todavia, o surgimento da obrigação tributária, por si só, não é suficiente, já que esta ainda não é dotada de certeza e liquidez. Logo, mostra-se necessário definir com exatidão o montante devido, o prazo para pagamento e o devedor, como forma de conferir exigibilidade a obrigação tributária.

Neste contexto, surge o denominado lançamento tributário, podendo ser conceituado como o procedimento administrativo tendente a verificar a ocorrência do fato gerador da obrigação correspondente, determinar a matéria tributável, calcular o montante do tributo devido, identificar o sujeito passivo e, sendo o caso, propor a aplicação da penalidade cabível (artigo 142 do Código Tributário Nacional).

Realizado o lançamento tem-se a constituição do chamado crédito tributário, sendo que este poderá sofrer as influências de causas de extinção, exclusão e suspensão, enumeradas nos artigos 151,156 e 175 do Código Tributário Nacional. Através de leitura dos dispositivos citados, verifica-se que uma das causas de extinção do crédito tributário é a chamada transação (artigo 156, inciso III, do Código Tributário Nacional). É esta a causa de extinção que iremos analisar neste momento, tendo sido disciplinada no artigo 171 do Código Tributário Nacional.

Inicialmente, deve-se lembrar que não há motivos para se confundir transação com parcelamento, pois esta configura causa de suspensão da exigibilidade do crédito tributário, enquanto aquela possui natureza de causa extintiva. Logo, no caso de descumprimento do parcelamento, o montante devido será exigido novamente na sua integralidade ou será cobrado apenas o saldo remanescente na data do descumprimento do parcelamento. Tal diferenciação já foi abordada pelos Tribunais brasileiros, entre eles o Superior Tribunal de Justiça ${ }^{6}$.

Feita a advertência acima, observa-se que a transação em matéria tributária possui uma particularidade quando comparada com a transação em Direito Privado, disciplinada pelo artigo 840 do Código Civil de 2002, cuja redação enuncia ser lícito aos interessados prevenirem ou terminarem o litígio mediante concessões mútuas. Como se vê, no Direito Civil a transação poderá ser celebrada com a finalidade de evitar ou encerrar o litígio por meio de concessões mútuas, enquanto no Direito Tributário a transação só poderá ser efetuada com o intuito de por fim ao litígio. Logo, pode-se dizer que em Direito Tributário exige-se que o crédito esteja efetivamente constituído para fins de transação, pois caso contrário a transação teria também finalidade preventiva.

Esta primeira diferença é ressaltada por Paulo de Barros Carvalho:

Ao contrário do que sucede no direito civil, em que a transação tanto previne como termina o litígio, nos quadrantes do direito tributário só se admite a transação terminativa. Há de existir litígio para que as partes, compondo seus mútuos interesses, transijam (1993, p. 308).

Outra característica essencial da transação em matéria tributária que a distingue da transação em direito civil é a exigência de lei que autorize a prática de tal ato. Tal pressuposto se mostra coerente com a

\footnotetext{
${ }^{6}$ Tributário. Execução Fiscal. Parcelamento do débito. Extinção da execução antes do adimplemento de todas as parcelas. Impossibilidade. O crédito tributário só se extingue nas hipóteses previstas no art. 156 do CTN, em que se não insere o parcelamento da dívida. O parcelamento do débito constitui mera dilação de prazo de pagamento, não extinguindo a execução antes do adimplemento da última parcela, no prazo, naquele consignado. Recurso provido. Decisão unânime. (REsp 468879-4/SP, rel. Min. Demócrito Reinaldo, j. 22.03.1995, DJU 24.04.1995, p. 10.387).
} 
natureza do tributo, pois este é expressamente definido pelo Código Tributário Nacional como sendo toda prestação pecuniária compulsória, em moda ou cujo valor nela se possa exprimir, que não constitua sanção de ato ilícito, instituída em lei e cobrada mediante atividade administrativa plenamente vinculada (artigo $\left.3^{\circ}\right)$.

Ou seja, se tributo é prestação compulsória e instituída por lei, obviamente apenas lei em sentido formal poderá autorizar a realização de transação em matéria tributária. Aliás, não se trata apenas de mera lei permissiva, mas de um conjunto de normas jurídicas que devem estabelecer os critérios e limites relativos à transação, conforme já advertiu Aliomar Baleeiro ao dizer que "a autoridade só pode celebrá-la com relativo discricionarismo administrativo, na apreciação das condições, conveniências e oportunidades, se a lei lhe faculta e dentro dos limites e requisitos por ela fixados." (1999, p. 905).

Portanto, transação em matéria tributária exige previsão legal e não pode apresentar como um de seus objetivos prevenir litígios, mas sim por fim a estes. Tais requisitos são nítidos e facilmente extraídos de simples interpretação literal da norma contida no artigo 171 do Código Tributário Nacional.

Outros elementos essenciais para fins de realização de transação em matéria tributária são a dúvida e a controvérsia. Nestas circunstâncias, a transação só poderá ser realizada quando estiverem presentes dúvidas relacionadas a determinada relação jurídica. Assim se manifesta Bernardo Ribeiro de Morais ao ressaltar que "a transação exige a existência de uma relação jurídica duvidosa, mesmo que seja o receio do resultado de um processo ainda não iniciado, e a existência de concessões mútuas, de parte à parte." (1997, p. 457).

Este também é o entendimento de Hugo de Brito Machado:

Geralmente, da transação decorre a extinção da relação obrigacional que albergava o litígio, mas tal extinção não constitui o objeto da transação. O que há de ficar extinto pela transação é o litígio, potencial ou já instalado, vale dizer, a incerteza quanto a relação jurídica, que era incerta e por isso mesmo abrigava pretensões opostas. Com a transação desaparece a lide, vale dizer, a pretensão resistida. Não necessariamente a relação que dava ensejo às pretensões (2005, p. 512).

Outra questão importante diz respeito ao momento em que poderá ocorrer a transação em matéria tributária. Em outras palavras, há na literatura debate se o instituto poderá ser aplicado apenas em lide judicializada ou também em controvérsias existentes na esfera administrativa.

Bernardo Ribeiro de Moraes entende ser possível a transação em matéria tributária apenas quando já existente uma demanda judicial:

Assim, verifica-se que a transação tem por objeto exclusivamente a terminação de litígio e o não litígio, dúvida ou controvérsia (como é no direito privado). Como litígio somente existe em processo contencioso, onde existe formação de juízo para a apreciação da causa, a transação somente pode ser realizada em processos judiciais (1997, p. 457).

Por outro lado, Paulo de Barros Carvalho sustenta que a transação tributária é cabível também na esfera administrativa:

Agora divergem os autores a propósito das proporções semânticas do vocábulo litígio. Querem alguns que se trate de conflito de interesses deduzido judicialmente, ao passo de que outros entendem a acepção a ponto de abranger as controvérsias meramente administrativas. Em tese, concordamos com a segunda alternativa. O legislador do Código não primou pela rigorosa observância das expressões técnicas, e não vemos por que o entendimento mais largo viria em detrimento do instituto ou da racionalidade do 
sistema. O diploma legal permissivo da transação trará, certamente, o esclarecimento desejado, indicando a autoridade ou as autoridades credenciadas a celebrá-la (1993, p. 532).

Em relação a esta questão, qual seja, o momento apropriado para a realização da transação em matéria tributária, também concordamos com a segunda alternativa. Não há motivos legais para se impedir a transação na esfera administrativa. Desta forma, o contribuinte ao receber a notificação de um lançamento tributário poderá apresentar proposta de transação, interrompendo-se temporariamente o prazo para apresentação de impugnação administrativa. Caso a transação não venha a ocorrer, o prazo seria "devolvido" ao contribuinte para que possa apresentar seus argumentos relativos à constituição do crédito realizada.

Em síntese, os elementos e requisitos essenciais da transação em matéria tributária foram apresentados acima, bem como outras questões relevantes. Desta forma, neste momento, podemos conceituar transação tributária de modo amplo, em observância ao que foi debatido até agora. E para fins de conceituação, utilizamos os ensinamentos de Luis Inácio Lucena Adams e Luiz Dias Martins Filho:

\footnotetext{
Então, infere-se que a transação em matéria tributária consiste em proposta de um acordo estabelecido pela Administração Pública, com base em uma norma legal, em que se objetiva por fim a um litígio, seja judicial ou administrativo, que verse sobre o pagamento de crédito fiscal envolto em controvérsia. Poderiam, nessas situações, ser feitas concessões por parte da Administração Pública, sempre tendo em vista o interesse maior, ou seja, o interesse público, consubstanciado numa efetiva e justa satisfação do crédito tributário. (2008, p. 5).
}

A transação em matéria tributária, entretanto, é objeto de polêmica quanto ao seu cabimento, pois este instituto poderia configurar violação ao princípio jurídico da indisponibilidade do interesse público. Nesta linha de raciocínio, podemos citar o pensamento de Eduardo Marcial Ferreira (MARTINS, 1998, p. 402), autor que sustenta ser a transação tributária uma impropriedade, devendo o artigo 171 do Código Tributário Nacional ser declarado inconstitucional ou ao menos revogado.

Portanto, partindo-se da premissa de que a transação prevista no artigo 171 do Código Tributário Nacional é sinônimo de conciliação, deve-se então discutir o aludido instituto à luz da indisponibilidade do interesse público, a fim de que se possa concluir se as concessões em matéria tributária, como forma de por fim ao litígio, são válidas ou devem ser afastadas. É esta a discussão que será feita no tópico a seguir.

\section{DA CONCILIAÇÃO EM MATÉRIA TRIBUTÁRIA E A INDISPONIBILIDADE DO INTERESSE PÚBLICO}

A análise jurídica e aplicação substancial do instituto da conciliação/transação enquanto técnica de solução de litígio, na seara privada para os direitos disponíveis, é questão que, muito embora pouco explorada, atualmente, já se encontra totalmente pacificada. Tal assertiva é facilmente verificada através da interpretação sistemática do que dispõe o Código Civil em conjunto com o Código de Processo Civil.

O primeiro diploma, em seu art. 841, é peremptório ao dispor que a transação/conciliação, apenas é possível em se tratando de direitos patrimoniais de caráter privado. O art. 125, inciso IV, do Código de Processo Civil, por sua vez, estabelece que compete ao Magistrado, "tentar, a qualquer tempo, conciliar as partes". Na mesma linha, tem-se inserido no bojo do mesmo diploma processual, para os procedimentos submetidos aos ritos comuns, sumário e ordinário, a previsão da designação, pelo Juiz, de audiência preliminar (art. 331), no intuito de aproximar as partes para uma possível conciliação, o que também ocorre naqueles procedimentos sob o crivo da Lei no 9.099/95 (Juizados Especiais).

Nucleus,v.12,n.1,abr.2015 
Entretanto, quando a questão relativa à conciliação é inserida nas discussões envolvendo direito público, como acontece nas questões de ordem tributária, torna-se bastante tormentosa a admissão de sua utilização como mecanismo de pacificação de conflitos.

Grande parte da doutrina e a também da jurisprudência dos Egrégios Tribunais pátrios, tradicionalmente, são resistentes no sentido de admitir a conciliação/transação em matéria tributária, pois a possibilidade de "a Administração Pública transacionar em Juízo historicamente enfrentou barreiras quase que intransponíveis alicerçadas especialmente no princípio da indisponibilidade do interesse público" (GAZDA, 2006).

Ou seja, em razão do princípio da indisponibilidade do interesse público, criou-se no Brasil, a cultura de resistir à aplicação da conciliação/transação para solução dos litígios judiciais ao argumento de que o Administrador não possui o poder de dispor livremente de um direito pertencente ao Estado, pois atua apenas como curador dos bens públicos. Segundo preconiza Celso Antônio Bandeira de Mello:

A indisponibilidade dos interesses públicos significa que, sendo interesses qualificados como próprios da coletividade - internos ao setor público -, não se encontram à livre disposição de quem quer que seja, por impropriáveis. O próprio órgão administrativo que os representa não tem disponibilidade sobre eles, no sentido de que lhe incumbe apenas curá-los - que também é um dever - na estrita conformidade do que predispuser a intentio legis (2002, p. 45).

Neste contexto, a doutrina tributária de maior expressão nacional é contundente em afirmar que à conciliação em matéria tributária, somente é permitida naqueles casos em que a lei expressamente previsse tal possibilidade, o que está praticamente pacificado. Todavia, a indagação a que se chega através desta assertiva é: A conciliação/transação nos casos autorizados pela legislação tributária violaria o princípio da indisponibilidade do interesse público?

Com a devida vênia, no entanto, aos que sustentam a impossibilidade de conciliação/transação em se tratando de matéria tributária, em virtude da força propalada pelo princípio da indisponibilidade do interesse público, é prudente frisar que no direito contemporâneo, analisado à luz da Constituição Federal, não se pode admitir este clássico posicionamento.

O princípio da indisponibilidade do interesse público deve ser interpretado sob a ótica dos postulados previstos na Carta Política de 1988, especialmente em sincronia com o princípio da eficiência (art. 37, caput) e duração razoável do processo ou celeridade processual (art. $5^{\circ}$, inciso LXXVIII), visto que, em determinados casos autorizados por lei e que o particular esteja imbuído da vontade de solucionar pacificamente o litígio, o Estado não poderá resistir à conciliação/transação em respeito tão somente aquele primeiro princípio.

$\mathrm{Na}$ análise do caso concreto, a utilização da conciliação/transação mesmo quando uma das partes envolvidas no litígio é o Estado (aqui entendido em todas as esferas: Federal, Estadual e Municipal), pode ser a melhor medida para atender os postulados constitucionais, sem, contudo, transgredir o princípio da indisponibilidade do interesse público.

Ou seja, existirá, na verdade, uma mitigação do princípio da indisponibilidade do interesse público, para que assim, seja possível a sua convivência harmônica com os postulados constitucionais da eficiência e duração razoável do processo, os quais também devem pautar o agir do Estado-Administração.

O administrador, curador dos bens estatais, verificando-se a existência prévia de lei tributária que permita a conciliação/transação, bem como a oportunidade e conveniência, possui um poder-dever de buscar a conciliação como forma pacífica de solução do litígio. A solução pacífica das controvérsias 
judiciais é, inclusive, um dos objetivos previstos no preâmbulo da Magna Carta de 1988, a qual expressa este compromisso. (GAZDA, 2006).

Ainda que seja consabido que o preâmbulo não possui força normativa, não se pode negar o seu caráter instrucional, que serve como norte para fins de interpretação do conteúdo inserido na Norma Jurídica Fundamental. Mesmo constituindo um marco importante no que concerne ao amplo acesso à justiça, a Lei Maior não cuidou de tratar de forma expressa e incisiva do instituto da conciliação, até pela cultura do litígio arraigada no pensamento dos juristas brasileiros.

Entretanto, o Estado, tendo em vista que o princípio da indisponibilidade do interesse público visa resguardar o interesse da própria coletividade, deve ter em mente que sua finalidade sempre recairá, no final, sobre o homem. Logo, para que o interesse de todos seja efetivamente alcançado pelo Estado, o princípio da indisponibilidade do interesse público, que não é absoluto, deve ser relativizado.

A movimentação do aparato jurisdicional ou a sua utilização por um lapso temporal extremamente delongado (anos e anos a fio), em determinados casos, pode se mostrar totalmente desnecessário e oneroso ao próprio Estado, motivo pelo qual a conciliação/transação acabará por ser a melhor forma de alcançar a observância do princípio da indisponibilidade do interesse público, como também do princípio da eficiência e da duração razoável do processo.

O Supremo Tribunal Federal, ao se deparar com a questão da possibilidade da conciliação/transação quando está em discussão litígio envolvendo o Estado, entendeu que existe situações que é preciso relativizar o princípio da indisponibilidade do interesse público, até para que seja ele próprio atendido pelo Administrador Público.

Segundo dispôs a Ministra Ellen Gracie:

Poder Público. Transação. Validade. Em regra, os bens e o interesse público são indisponíveis, porque pertencem à coletividade. É, por isso, o Administrador, mero gestor da coisa pública, não tem disponibilidade sobre os interesses confiados à sua guarda e realização. Todavia, há casos em que o princípio da indisponibilidade do interesse público deve ser atenuado, mormente quando se tem em vista que a solução adotada pela Administração é a que melhor atenderá à ultimação deste interesse. ${ }^{7}$

Neste viés, através da análise pormenorizada dos princípios constitucionais inseridos na Constituição Federal, percebe-se que a conciliação em determinados casos, existindo previsão da legislação tributária para sua realização (art. 171, CTN), não constituirá ofensa a este postulado ou ao princípio da indisponibilidade do interesse público, pois se mostrará como medida que melhor refletirá os anseios do princípio da eficiência e da duração razoável do processo, os quais, como já aduzido, também regem as relações Estatais. Depreende-se dos ensinamentos de Hely Lopes Meirelles, que:

O princípio da eficiência exige que a atividade administrativa seja exercida com presteza, perfeição e rendimento funcional. É o mais moderno princípio da função administrativa, que já não se contenta em ser desempenhada apenas com legalidade, exigindo resultados positivos para o serviço público e satisfatório atendimento das necessidades da comunidade e de seus membros (2007, p. 96).

Não é bastante que o administrador proceda nos estritos termos do princípio da indisponibilidade do interesse público, visto que o direito deve ser interpretado em sua totalidade, como um sistema único e harmônico. Existe, sim, o dever de respeito a esse postulado, mas isto não basta para que o interesse do Estado e, por consequência, da coletividade prevaleça.

\footnotetext{
7 BRASIL, Supremo Tribunal Federal. RE: 253.885/MG, Rel. Min. Ellen Gracie, 21 de junho de 2002. Disponível em: <http://redir.stf.jus.br/paginadorpub/paginador.jsp?docTP=AC\&docID=258322. Acesso em: 14 fev. 2014.
} 
Ademais, deve acrescentar-se a isto, que o princípio da indisponibilidade do interesse público guarda estrita relação com o princípio da dignidade da pessoa humana, "significando que a vontade legítima deve preponderar sobre a vontade egoisticamente articulada, observando-se que a vontade egoísta pode em muitos casos ser a do Estado e aí não poderá prevalecer" (GAZDA, 2006).

Em casos devidamente regulamentados pela lei tributária, aduzir de forma veemente que não é possível a conciliação em matéria tributária ao argumento único e exclusivo de que estaria violando o princípio da indisponibilidade do interesse público, seria uma forma de fazer prevalecer à vontade do Estado mesmo não existindo plausibilidade para tanto, afetando, por consequência, além dos princípios da eficiência e da duração razoável do processo, o princípio da dignidade da pessoa humana, visto que, como já sublinhado outrora, o fim do Estado se esgota no homem, elemento componente deste.

Neste contexto, se o interesse público é também aquele da própria coletividade, o Estado, ao fazer prevalecer sua vontade mesmo que diante da ausência de melhores resultados efetivos ao Poder Público, não estará atendendo o próprio princípio da indisponibilidade do interesse público e, também, os princípios da eficiência, duração razoável do processo e dignidade da pessoa humana, pois na hipótese, existindo lei tributária, seria mais viável a realização da conciliação/transação.

\section{CONCLUSÃO}

Conforme exposto acima, a conciliação enquanto forma alternativa de solução de litígio, no âmbito do direito tributário é admitida por força do art. 171, do Código Tributário Nacional, naqueles casos em que houver legislação autorizando a sua realização. Esta possiblidade é amplamente aceita pela doutrina que trata do assunto, entendendo, inclusive, que a conciliação pode ser realizada tanto no âmbito administrativo quanto no judicial.

A questão, no entanto, se torna bastante tormentosa quando se está diante daquela corrente que sustenta a impossibilidade da conciliação em matéria tributária por força do princípio da indisponibilidade do interesse público. Renomados autores, através de consistentes argumentos, sustentam que não é possível à utilização da técnica da conciliação no direito tributário por encontrar óbice no mencionado princípio.

Entretanto, tendo em vista que a finalidade do Estado sempre recairá sobre o homem (coletividade), o princípio da indisponibilidade do interesse público deve sempre buscar atender o interesse desses componentes.

Em razão disto, em determinados casos os quais a lei tributária autorize a transação, o referido preceito restará mitigado, conforme já sedimentado pelo Supremo Tribunal Federal, a fim de que não haja movimentação desnecessária do Poder Judiciário ou a sua utilização por tempo em demasia, motivo pelo qual a conciliação será a melhor forma de alcançar e atender aos anseios buscados pelo princípio da indisponibilidade do interesse público.

Não basta apenas a simples observância ao princípio da indisponibilidade do interesse público, é preciso realizar a análise do instituto da conciliação no direito tributário à luz dos princípios constitucionais da eficiência (art. 37, caput), da duração razoável do processo (art. $5^{\circ}$, inciso LXXIV) e do princípio da dignidade da pessoa humana (art. $1^{\circ}$, inciso III), pois naqueles casos em que existir lei autorizadora, o Poder Público possui o dever de solucionar pacificamente o conflito.

O princípio da indisponibilidade do interesse público, neste prisma, deve coexistir de forma harmônica com os postulados constitucionais acima citados, visto que todos regem a forma de agir do Estado, razão pela qual se conclui pela plena possibilidade da conciliação em matéria tributária, não 
constituindo, portanto violação à indisponibilidade do interesse público quando exercida nos casos em que a lei permitir.

\section{REFERÊNCIAS}

ALVIM, A.. Manual de direito processual civil. 14 ed. São Paulo: RT, 2011.

ATALIBA, G.. Hipótese de incidência tributária. 6. ed. São Paulo: Malheiros, 2012.

BALEEIRO, A.. Direito Tributário Brasileiro. 11. ed. Atualizada por Misabel Abreu Machado Derzi. Rio de Janeiro: Forense, 1999.

BRASIL, Supremo Tribunal Federal. RE: 253.885/MG, Rel. Min. Ellen Gracie, 21 de junho de 2002. Disponível em: http://redir.stf.jus.br/paginadorpub/paginador.jsp?docTP=AC\&docID=258322 . Acesso em: 14 fev. 2014.

CARVALHO, P.de B.. Curso de Direito Tributário. 6. ed. São Paulo: Saraiva, 1993.

COOLEY, J.W. A advocacia na mediação. Brasília: UNB, 2001.

DINAMARCO, C.R.. Instituição de direito processual civil. V. 1. 5. ed. São Paulo: Malheiros, 2004.

FIUSA, C.. Teoria geral da arbitragem. Belo Horizonte: Del Rey, 1995.

GAZDA, E.. Administração Pública em juízo: poder-dever de transigir. Direito Federal: Revista da Associação dos Juízes Federais do Brasil. v. 23, n. 83, p. 131-158, jan/mar 2006.

GUIMARÃES, D.T.. Dicionário técnico jurídico. 10. ed. São Paulo: Rideel, 2010.

OLIVEIRA JR, E.R. de. Acesso à justiça e as vias alternativas para solução de controvérsias: mediação, conciliação e arbitragem. Jus Navigandi, Teresina, ano 16, n. 3069, 26 nov. 2011. Disponível em: <http://jus.com.br/artigos/20517>. Acesso em: 16 fev. 2014.

MACHADO, H.de B.. Comentários ao Código Tributário Nacional. Vol. III, São Paulo: Atlas, 2005.

MARTINS, I.G.da S. (coord.). Comentários ao código tributário nacional. São Paulo: Saraiva, 1998.

MARTINS FILHO, L.D.; ADAMS, L.I.L.. A transação no Código Tributário Nacional (CTN) e as novas propostas normativas de lei autorizadora. In: SARAIVA FILHO, Oswaldo Othon de Pontes; GUIMARÃES, Vasco Branco. Transação e arbitragem no âmbito tributário. Belo Horizonte: Fórum, 2008.

MEIRELLES, H.L.. Direito administrativo brasileiro. 33. ed. São Paulo: Malheiros, 2007.

MELLO, C.A.B.de. Curso de Direito Administrativo. 14. ed. São Paulo: Malheiros, 2002.

MORAES, B.R.de. Compêndio de Direito Tributário. Rio de Janeiro: Forense, 1997.

SOUSA, L.A.. A utilização da mediação de conflitos no processo judicial. Jus Navigandi, Teresina, ano 10, n. 568, 26 jan. 2005. Disponível em: http://jus.com.br/artigos/6199 . Acesso em: 17 fev. 2014. 
